\title{
Micropropagación de Hypericum goyanesii, una especie en vía de extinción
}

\section{Micro-spreading of the Hypericum goyanesii specie, an endangered specie}

Fecha de recepción: 28 de marzo de 2008

Fecha de aceptación: 14 de julio de 2008

Jaime Alonso Pedroza-Manrique'; Maria Victoria Montes-Villegas.

\section{RESUMEN}

En este trabajo se evaluó el cultivo de tejidos vegetales in vitro como una alternativa en la propagación y preservación de Hypericum goyanesii, especie en vía de extinción. Se determinó que el efecto que tiene el hipoclorito de sodio ( $1.5 \%$ por $5 \mathrm{~min}$.) y el benlate, como agentes desinfectantes de las secciones de nudos, permiten obtener el mayor porcentaje de brotes adaptados a condiciones in vitro. Los nudos con yemas axilares se sembraron en medios Murashige \& Skoog (1962) enriquecido con la Auxina Acido Indol Butírico (AIB) $\left(0 ; 0.5 ; 1.0 ; 1.5 \mathrm{mg} \cdot \mathrm{L}^{-1}\right)$ y la Citoquinina 6-bencilaminopurina $(\mathrm{BAP})\left(0 ; 0.5 ; 1.0 ; 1.5 \mathrm{mg} . \mathrm{L}^{-1}\right)$. Se determinó que la utilización de 0.5 mg. $\mathrm{L}^{-1}$ de Bencilaminopurina permite la obtención del mayor número de plántulas, estableciendo las condiciones más adecuadas para la propagación in vitro de Hypericum goyanesii.

\section{Palabras clave}

Hypericum goyanesii, micropropagación, plantas en vías de extinción, AIB, BAP.

\section{ABSTRACT}

This work evaluated the plant tissue culture like a propagation and preservation alternative of Hypericum goyanesii, an endemic threatened shrub. It was found that $\mathrm{NaOCl}(1.5 \%$ by $5 \mathrm{~min}$.) and Benlate, used as disinfectants of $H$. goyanesii buds, showed the best results in regards to the percentage of buds adapted to in vitro conditions. Nodes with lateral buds were cultured on the basal medium Murashige and Skoog (1962), enriched with Indol Butyric Acid (IBA) $\left(0 ; 0.5 ; 1.0 ; 1.5 \mathrm{mg} . \mathrm{L}^{-1}\right)$ and 6-benzylaminopurine (BAP) $\left(0 ; 0.5 ; 1.0 ; 1.5 \mathrm{mg} \cdot \mathrm{L}^{-1}\right)$. The use of $0.5 \mathrm{mg} \cdot \mathrm{L}^{-1}$ of 6 -benzilaminopurine allows obtains greater number of in vitro plants, establishing better conditions for mass propagation of $H$. goyanesii.

\section{Keywords}

Hypericum goyanesii, micropropagation, endangered plant, IBA, BAP.

1 Universidad Distrital Francisco José de Caldas, Facultad de Ciencias y Educación. Proyecto Curricular de Licenciatura en Biología, Teléfonos: 3419618, Fax: 3419619, Correo electrónico: jpedroza@udistrital.edu.co 


\section{INTRODUCCIÓN}

Teniendo en cuenta que Colombia es un país megadiverso y conociendo los peligros de desaparición que afronta esta diversidad, es necesario emplear estrategias y metodologías que aseguren la perpetuación de las especies vegetales, especialmente aquellas que se encuentran en vía de extinción. Actualmente son evidentes las severas amenazas que se ciernen sobre los ecosistemas de montaña en el mundo entero, pero especialmente los daños se han calificado como extremos y significativos en los Andes (Okada, 2001).

Dentro de estos efectos ambientales se clasifican varias especies vegetales con altas probabilidades de desaparecer en ecosistemas tan importantes como los páramos. De hecho, los páramos deben convertirse en áreas protegidas, porque conforman la gran reserva de agua con que hoy se cuenta, situación que motiva el desarrollo de estudios ecológicos, fisiológicos y de recuperación basados en los modelos de desarrollo sostenible, referentes a la conservación y protección ambiental, donde las especies vegetales, especialmente las que se encuentran en vía de extinción, justifican su propagación mediante técnicas biotecnológicas.

Hypericum goyanesii se encuentra restringida a la franja del subpáramo en el departamento de Cundinamarca y ha sido catalogada dentro del estado Vulnerable (Vu) (Instituto Alexander von Humbolt, 1997). Su estado actual es muy riesgoso debido a la rápida ampliación de la frontera agrícola, la deforestación, la disminución de cobertura vegetal natural, quemas, talas y erosión. Además, esta especie se utiliza en la preparación de aceites y té contra enfermedades de los riñones, sus hojas y flores se utilizan en la preparación de extractos alcohólicos y aceites esenciales que controlan quemaduras y procesos antisépticos.
Este trabajo evaluó el cultivo de tejidos vegetales in vitro como una alternativa en la preservación y recuperación de $H$. goyanesii, en el sentido de pertenencia, protección y conservación del patrimonio natural, porque la propagación in vitro es una fuente importante en la conservación del germoplasma vegetal que ofrece bienes y servicios a la humanidad.

\section{Materiales y métodos}

Material vegetal y adaptación a condiciones in vitro.

La recolección del material vegetal se realizó en el páramo de Cruz Verde, localizado a $4^{\circ} 33^{\prime}$ latitud norte y $74^{\circ} 72^{\prime \prime}$ latitud este, a una distancia de 3300-3400 m. sobre el nivel del mar. Se extiende a los lados de la carretera que conduce al municipio de Choachí Cundinamarca, a $10 \mathrm{Km}$. de Bogotá.

El material vegetal se seleccionó escogiendo los ejemplares de $H$. goyanesii completamente sanos. Se recolectaron ramas de $50 \mathrm{~cm}$. de longitud aproximadamente, que posteriormente fueron conservadas en toalla de papel humedecida y empacadas en bolsas

Cuadro 1. Tratamientos que evalúan el efecto de la concentración del hipoclorito de sodio y el tiempo de exposición, en la obtención de explantes de H. goyanesii libres de patógenos bajo condiciones in vitro.

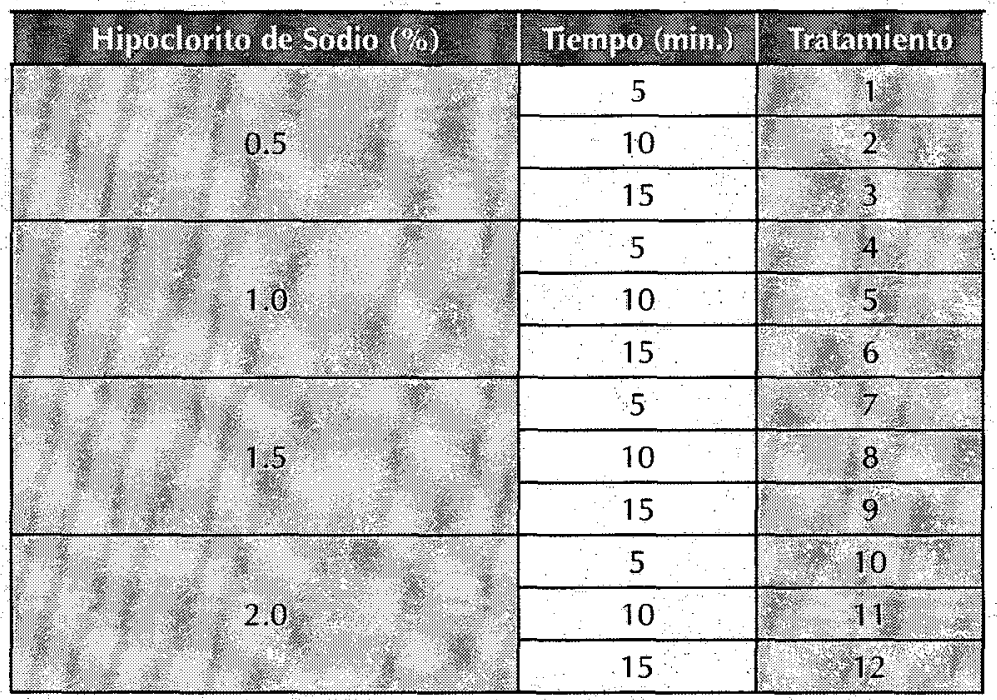


plásticas para el transporte al laboratorio de Biotecnología Vegetal de la Universidad Distrital FJC.

Las ramas fueron sumergidas en una solución de Benlate al 2\% durante una hora y posteriormente se realizaron cuatro enjuagues consecutivos con solución jabonosa y agua destilada, estéril. Posteriormente, se sumergieron en una solución antioxidante enriquecida con ácido cítrico y ascórbico a 100 mg. $L^{-1}$ durante una hora. Luego se sometieron a una solución humectante compuesta por agua destilada y agente tensoactivo Tween 80 ( 3 gotas por cada $100 \mathrm{ml}$ de agua) durante 10 minutos. Enseguida, el material vegetal se pasó por 2 enjuagues con agua destilada durante 5 minutos cada uno para retirar los residuos del Tween 80 .
Cuadro 2. Tratamientos que evalúan el efecto combinado del AlB y del BAP en el desarrollo morfogenético de nudos y yemas axilares de $H$. goyanesii bajo condiciones in vitro

\begin{tabular}{|c|c|c|}
\hline 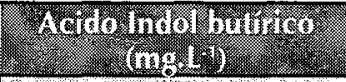 & Jom & 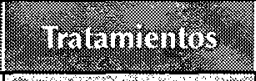 \\
\hline & 0.0 & 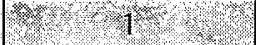 \\
\hline & 0.5 & (3) 2 \\
\hline & 1.0 & $27: 3$ \\
\hline & 1.5 & 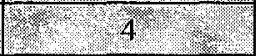 \\
\hline & 0.0 & 1.0 .5 \\
\hline & 0.5 & $\sqrt{2} 6$ \\
\hline & 1.0 & 2. (7.7.7. \\
\hline & 1.5 & 68 \\
\hline & 0.0 & 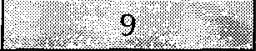 \\
\hline & 0.5 & 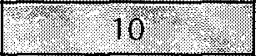 \\
\hline & 1.0 & 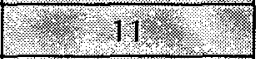 \\
\hline ? & 1.5 & $(12)=$ \\
\hline & 0.0 & 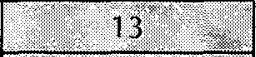 \\
\hline & 0.5 & 170.14 \\
\hline & 1.0 & 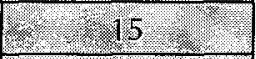 \\
\hline 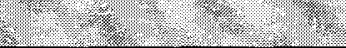 & 1.5 & 10.16 \\
\hline
\end{tabular}

Los nudos se sumergieron en solución de etanol al $70 \%$ durante 30 segundos y enseguida se resuspendió en solución de Hipoclorito de sodio en las siguientes concentraciones: $0.5,1.0,1.5$, y $2.0 \%$ durante 5, 10, y 15 minutos, para un total de 12 tratamientos (cuadro 1). Finalmente, se realizaron tres enjuagues en agua destilada y estéril, previo a la siembra en los medios de cultivo.

\section{Medios utilizados y condiciones de cultivo.}

Como medio básico en el establecimiento in vitro de los nudos de $H$. goyanesii se utilizó el de Murashige y Skoog (1962), enriquecido con las siguientes dos fitohormonas en el cultivo de nudos: el ácido indol butírico $(\mathrm{AIB})\left(0 ; 0.5 ; 1\right.$ y $\left.1.5 \mathrm{mg} . \mathrm{Ll}^{-1}\right)$ y la bencilaminopurina (BAP) $\left(0 ; 0.5 ; 1\right.$ y $\left.1.5 \mathrm{mg} . \mathrm{L}^{-1}\right)$ para un total de 16 tratamientos (cuadro 2). A todos los medios se les suministró 3\% (w/v) de sacarosa y $0.8 \%(\mathrm{w} / \mathrm{v})$ de agar. $\mathrm{El} \mathrm{pH}$ de los medios fue ajustado a 5.8, antes de ser esterilizados a una presión de $1.06 \mathrm{Kg} . \mathrm{cm}^{-2}$ por 20 minutos.
Tan pronto fueron sembrados los explantes en los diferentes medios, se incubaron en un cuarto de crecimiento a temperatura ambiente de $23^{\circ} \mathrm{C}$, a 25-30 $\mu \mathrm{mol} \mathrm{m}{ }^{-2} \mathrm{~s}^{-1}$ (Tubos fluorescentes de luz día FL-20D/18, 20 W, China Electric Co., Taipei) y un fotoperiodo de 12 horas de irradiación lumínica.

\section{Análisis estadístico}

El experimento fue desarrollado bajo un diseño completamente al azar con arreglo factorial $4 \times 4$, con concentraciones de $0 ; 0.5 ; 1$ y $1.5 \mathrm{mg} . \mathrm{L}^{-1}$ para el ácido indol butírico (AIB) y $0 ; 0.5 ; 1$ y 1.5 mg. $\mathrm{L}^{-1}$ para la bencilaminopurina (BAP), en la adaptación in vitro de nudos. En cada uno de los 16 tratamientos se trabajaron diez réplicas, donde cada réplica estaba representada por un frasco de cultivo, con 1 explante, para un total de 160 unidades experimentales. Los datos fueron estadísticamente analizados en términos de porcentaje y los promedios de los tratamientos fueron comparados empleando la 
prueba de $X^{2}$ (ji cuadrado) (Steel y Torrie, 1985) a fin de establecer el mejor tratamiento de micropropagación de $H$. goyanesii.

\section{Resultados y discusión.}

Adaptación a condiciones in vitro.

El efecto de la concentración del hipoclorito de sodio y el tiempo de exposición de los nudos a este desinfectante, a fin de obtener explantes libres de patógenos, presentó diferencias estadísticas altamente significativas $(\mathrm{P}<0.01)$ entre los 12 tratamientos evaluados.

El uso combinado del fungicida benlate y el hipoclorito de sodio (Tratamiento siete: $\mathrm{NaOCl}$ al 1.5\% por 5 minutos), presentó un óptimo efecto en la desinfección de los explantes, logrando un $100 \%$ de explantes libres de patógenos.

La obtención de material vegetal desinfectado y viable es difícil porque las soluciones utilizadas para desinfectar los explantes deben preservar el tejido pero al mismo tiempo destruir cualquier contaminante fungal o bacteriano. Uribe y Cifuentes (2004), afirman que el principal problema en la etapa de establecimiento es la contaminación fúngica, lo que da paso, posteriormente, a una predominancia de contaminación por bacteria, concluyéndose que las condiciones de pretratamiento de la planta madre son un elemento de suma importancia para el éxito del cultivo.

Según Marulanda (2004) ninguno de los métodos de desinfección utilizados comúnmente son eficaces para evitar problemas asociados a altos niveles de contaminación por hongos y bacterias, inconveniente que ha sido reportado en varias investigaciones relacionadas con la propagación in vitro (Pedersen et al., 1992).

De acuerdo con Fontúrbel (2006), existen esporas de hongos y bacterias enquistadas que no se pueden eliminar fácilmente con agentes químicos de acción superficial, como el hipoclorito de sodio la combinación con fungicida resulta mucho más efectiva, porque el benlate es sistémico con actividad sobre ectoparásitos y endoparásitos por contacto. Su ingrediente activo es el Metilbencimidazolil que interfiere con la síntesis del DNA. Las concentraciones elevadas del desinfectante eliminan por completo la posible contaminación, aunque puede reducir el número de explantes verdes.

De tal manera se encuentra que a menor concentración del desinfectante es mayor el número de explantes verdes pero el porcentaje de contaminación es mayor (De Liñan, 1997).

Igualmente, se ha establecido que el hipoclorito de sodio, en complemento con un fungicida, varía de una especie a otra, por lo que en algunos estudios experimentales de la iniciación de cultivos in vitro de algunas especies se demostró que el uso del hipoclorito de sodio era suficiente al someterse a una doble desinfección con el mismo, al 1.5\% y al $3 \%$ respectivamente (Tapia, 2004).

El hipoclorito de sodio como agente desinfectante ha sido empleado durante mucho tiempo porque es reconocido su efectivo poder germicida y los pocos efectos de toxicidad en los tejidos, aunque se le atribuye, en muchas ocasiones, la necrosis y muerte de los tejidos (Benítez e Higuera, 1992; Vadillo, 2004; Albany et al., 2006).

Estos resultados demuestran claramente que la toxicidad generada por un agente desinfectante sobre un tejido depende de su clase y procedencia porque estos efectos pueden diferir de un organismo a otro. En términos generales, se encontró que a medida que se incrementa la concentración y el tiempo de exposición de los explantes al desinfectante en cada uno de los tratamientos, el porcentaje de contaminación disminuye al igual que el porcentaje de explantes verdes; es decir, que a menor concentración del des- 
infectante es mayor el número de explantes verdes pero el porcentaje de contaminación es mayor.

Hubo presencia de hongos, como Aspergillus sp, Penicillium sp $y$ Fusarium sp y Alternaria sp reportados como patógenos frecuentes en el cultivo de tejidos. Uno de los contaminantes más frecuentes sobre los explantes de $H$. goyanesii fue la levadura Rodhotorola reportada como coayudante en la fijación del nitrógeno, sin embargo, ocasionó muerte total a los explantes que infectó.

Agrios (1988) afirma que generalmente se considera que la simbiosis que se establece entre una planta hospedera y algún microorganismo beneficia igualmente a ambos organismos.

Sin embargo, es probable que bajo ciertas condiciones nutricionales uno de ellos domine y obtenga mayor beneficio que el otro hasta el punto de perjudicarlo. De hecho, el nitrógeno presente en los medios de cultivo provoca un rápido crecimiento de Rodhotorola, impidiendo la absorción de este mineral por los explantes vegetales cultivados, situación que provoca su muerte.

De otra parte, es importante tener en cuenta el tamaño de los explantes, porque entre más pequeños sean, mejor será el campo de acción del desinfectante y mejores serán los resultados, puesto que al interior de los tejidos vegetales se pueden encontrar hongos $y$ demás patógenos que se desarrollan más viablemente en los cultivos in vitro gracias a la composición del medio MS (Albany et al., 2006).

\section{Cultivo de nudos.}

Según los análisis de varianza, existe una diferencia altamente significativa $(\mathrm{P}<0.01)$ entre los tratamientos que evalúan el efecto del AIB y del BAP tanto en el proceso de caulogénesis como en el de rizogénesis.

Caulogénesis. En el proceso de caulogénesis se regeneraron 24 brotes 15 días después de sembrados los

CENTRO DE INVESTIGACIONES Y DESARROLLO CIENTÍFICO nudos en el tratamiento $2\left(0.0 \mathrm{mg} . \mathrm{L}^{-1}\right.$ de AIB y 0.5 mg. $\mathrm{L}^{-1}$ de BAP) (figura 1A). Con este tratamiento se obtuvo la mayor cantidad de brotes en poco tiempo, al compararlos con los tratamientos $1\left(0.0 \mathrm{mg} . \mathrm{L}^{-1}\right.$ de AIB y $0.0 \mathrm{mg}$. L-1 de BAP), 6 ( $0.5 \mathrm{mg} . \mathrm{L}^{-1}$ de AIB y $0.5 \mathrm{mg}$. $\mathrm{L}^{-1}$ de BAP) y $12\left(1.0 \mathrm{mg} . \mathrm{L}^{-1} \mathrm{de}\right.$ AIB y 1.5 mg. $\mathrm{L}^{-1}$ de BAP) que produjeron 15,18 y 13 brotes respectivamente.

Se encontró también que a medida que se incrementan las concentraciones de la auxina (AIB) disminuye el número de brotes regenerados, igualmente se observa que a medida que se incrementan las concentraciones de la citoquinina (BAP) se presenta. un descenso drástico en el número de brotes regenerados, lo que se puede catalogar como un efecto lineal negativo.

Según Jiménez et al, (2004) y Uribe y Cifuentes, (2004), los mejores resultados de respuesta organogénica de los segmentos nodales cultivados in vitro varían de acuerdo a la relación hormonal AIB:BAP.

Según Pérez y Jiménez (1995) y Barraza (2004), para aumentar el número de brotes en condiciones in vitro es efectivo utilizar el BAP y complementar con otros fitohormonas de crecimiento para mejorar el desarrollo de los explantes y brotes bajo condiciones in vitro, situación que demuestra la importancia de las hormonas de crecimiento en la micropropagación de plantas. De otra parte, es importante tener en cuenta que el tratamiento dos es más práctico y reduce costos al inducir una respuesta morfogenéti$\mathrm{Ca}$, a partir de un solo regulador de crecimiento para la propagación masiva de $H$. goyanesii.

En términos generales, se evidenció la importancia de la adición de citoquininas exógenas para balancear los niveles endógenos de los reguladores de crecimiento e inducir una respuesta morfogenética en nudos con yemas axilares en Hypericum goyanessii, igualmente se observa que para la formación de plantas completas es innecesaria la adición de auxinas exógenas porque, como lo afirman Orellana 
(1998) y Fernández (2004), los brotes jóvenes en desarrollo son una rica fuente en la producción de auxinas.

Rizogénesis. Al igual que en la caulogénesis, en el proceso de rizogénesis el tratamiento 2 (AIB 0.0 $\mathrm{mg} . \mathrm{L}^{-1}-$ BAP $0.5 \mathrm{mg} . \mathrm{L}^{-1}$ ) fue el que arrojó mejores resultados, porque se obtuvo un mayor número de raíces (41) en 15 días (figura 1B). También es importante considerar que la respuesta de los nudos a la presencia del AIB para la producción de raíces no fue la más favorable, porque a medida que aumentaba la concentración de esta fitohormona, disminuía el número de raíces regeneradas. De igual forma, en los tratamientos 1,2, 3 y 4, libres de esta fitohormona, la producción de raíces fue mayor en comparación con el aumento sucesivo de su concentración.

Esta respuesta sucedió porque, según Herman (2005), las auxinas tienden a acumularse en las células de las plantas, debido a que no hay sistemas enzimáticos ni procesos naturales que le permitan a la planta desecharlas, por lo cual su aumento en las células puede llegar a ser tóxico, lo cual explicaría por qué a medida que aumentan sus concentraciones en el cultivo se inhibe la formación de raíces. De otra parte, según Salisbury y Ross (2000), el crecimiento radicular está regulado por el balance entre la auxina y el etileno, débido a que las primeras estimulan la producción del último. Por esta razón, al agregar grandes cantidades de auxinas, se aumenta la producción de etileno, que a su vez inhibe el crecimiento radicular (Acosta, 2004).

Esta respuesta posiblemente se relaciona con el hecho de que los niveles endógenos de auxina son altos en los nudos de $H$. goyanesii cultivados in vitro, y la adición exógena inhibe el proceso, bien sea por toxicidad o por habituación celular (Taiz y Zeiger, 1998).

También se puede inferir que el incremento en las concentraciones de los reguladores de crecimiento afecta el desarrollo de la organogénesis, lo cual coin- cide con lo mencionado por Olivera (2000), en el que se considera que los cambios en las concentraciones de los reguladores de crecimiento pueden producir cambios y alteraciones en el desarrollo de las plantas, los cuales afectan su metabolismo.

De otra parte, se debe tener en cuenta que los procesos morfogenéticos no sólo se encuentran influenciados por las fitohormonas de crecimiento sino también por otros factores no hormonales como las concentraciones de azúcares y los efectos físicos como la luz y la calidad del tejido empleado en el cultivo in vitro (Hartman et al., 1997).

En términos generales, estos resultados indican que la rizogénesis a partir de nudos en $H$. goyanesii no es independiente de la adición exógena de auxinas al medio de cultivo. Segura (2000) y Pedroza et al, (2005) afirman que muchos efectos de las citoquininas pueden explicarse por su interacción con las auxinas, porque ambas hormonas participan en el control mutuo de su abundancia y, en general, las citoquininas incrementan los niveles de auxinas mientras que las auxinas disminuyen las concentraciones de citoquininas activas. Esto explica la rizogénesis que se produjo en presencia de la citoquinina (BAP), lo que indica que posiblemente los niveles endógenos de auxinas en $H$. goyanesii son elevados con relación a los de citoquininas.

Jiménez (1998), afirma que un balance apropiado entre auxinas y citoquininas en el medio de cultivo es necesario para la formación de plantas a partir de meristemos, ápices o yemas.

Este balance está determinado por las concentraciones endógenas de auxinas y citoquininas presentes en el explante, las cuales dependen de la especie y del tipo de explante. Esto se debe muy seguramente a que la adición exógena de auxinas al medio de cultivo generó toxicidad, debido a que los niveles endógenos de este regulador son altos en $\mathrm{H}$. goyanesii lo que provocó disminución en la respuesta morfogenética. 
Estos resultados demuestran el efecto que ejercen los reguladores de crecimiento en la respuesta morfogenética del explante. Igualmente se hace evidente el efecto de las auxinas en la elongación celular y en la proliferación de raíces, con lo que se puede corroborar la importancia del balance endógeno - exógeno de auxinas y citoquininas en la propagación efectiva de una especie vegetal, teniendo en cuenta que ambos reguladores mantienen y controlan mutuamente los niveles endógenos de sí mismos.

Según un estudio realizado para la propagación clonal in vitro de Agave Arizónica, la caulogénesis se promovió exitosamente sobre los explantes de esta planta en ausencia de las auxinas y altas concentraciones de citoquininas, lo cual indica la presencia de dichos reguladores del crecimiento en la caulogénesis de esta especie vegetal (Yépez y Vargas, 2003). Además, Rodríguez y Rodríguez (2003), afirman que los reguladores de crecimiento actúan como estimuladores en pocas cantidades, mientras que en concentraciones excesivas actúan como inhibidores.

En términos generales, se logra la producción de plantas completas de $H$. goyanesii obtenidas a partir de los nudos cultivados en medios MS enriquecido con $0.5 \mathrm{mg} . \mathrm{L}^{-1}$ de BAP, con un sistema caulinar $\mathrm{y}$ radicular bien desarrollado (figura 2 ).

\section{CONCLUSIONES}

El hipoclorito de sodio puede ser empleado como desinfectante superficial de nudos en $H$. goyanesii al $05 \%$ durante $5 \mathrm{~min}$. fortaleciendo su efecto mediante la combinación con el funguicida Benlate al $2 \%$ durante 1 hora.

Para inducir caulogénesis y rizogénesis a partir de nudos con yemas axilares de $H$. goyanesii se necesita enriquecer el medio MS con 0.5 mg. $\mathrm{L}^{-1}$ de la citoquinina BAP.

No se requiere adición de auxinas exógenas al medio MS de cultivo para inducir rizogénesis a partir de nu- dos con yemas axilares en $H$. goyanesii, debido a que el AIB inhibe la respuesta morfogenética del explante.

El balance Auxina : Citoquinina esta relacionado íntimamente con los niveles endógenos de estos reguladores en los nudos de $H$. goyanesii cultivados in vitro, así como su adición al medio de cultivo, gracias a su sinergismo, que se evidencia en una eficiente respuesta morfogenética por parte de los tejidos.

Agradecimientos: Este trabajo fue financiado por la Facultad de Ciencias y Educación de la Universidad Distrital Francisco José de Caldas.

\section{BIBLIOGRAFÍA}

Acosta, M. (2004). Función del transporte polary lateral en la formación de gradientes longitudinal y radial de auxina. Relación con el crecimiento, el enraizamiento y los valores de ploidia celular. Universidad de Murcia. En: metabolismo y modo de acción de Fitohormonas. España: Ed. Universidad de Salamanca, $41 \mathrm{p}$.

Agrios, G. (1988). Fitopatología. México: Limusa, 477 p.

Albany, N; Vilchez, J.; León, S.; de Sierralta, M.; Molina, M; Chacíl, P. (2006). Una metodología para la propagación in vitro de Aloe vera. Universidad del Zulia Venezuela, Facultad de Agronomía. Rev. Fac. Agron. 23, pp. 213-222.

Barraza, L. C. (2004). Micropropagación de Rhodophiala Phycelloides (Herb.) Hunz. Trabajo de grado de Investigación (Magíster en Ciencias Vegetales) Pontificia Universidad Católica de Chile. Facultad de Agronomía e Ingeniería Forestal Dirección de Investigación y Postgrado.

Benítez, M.; Higuera, M. (1992). Eficiencia in vitro del hipoclorito de sodio $2.5 \%$ combinado con $R C P$ rep, como coadyudante para la ambientación de conductos radiculares. Trabajo de grado (En- 
dodoncista). Pontificia Universidad Javeriana. Facultad de Odontología. Departamento de post- grado y educación continuada. Santa fé de Bogotá, pp. 52-58.

De Liñan, V. (1997). Farmacología vegetal. Barcelona: Ediciones Aerotécnicas. SL., pp. 108-110.

Fernández B. (2004). Niveles de citoquininas endógenas y actividad citoquinina oxidasa/deshidrogenasa en estados juveniles de Pinus sylvestris. Universidad de Oviedo. En: metabolismo y modo de acción de Fitohormonas. España: Ed. Universidad de Salamanca, 47 p.

Fontúrbel, R. F. (2006). Los vitro patógenos: consideraciones generales, detección y eliminación. Revista El portal de Biología y Ciencias de la Salud: 6, pp. 23-28.

Hartman, H.; Kester, D.; Davies, F.; Geneve, R. (1997). Plant propagation: principles and practices. Sixth edition. New Jersey: Prentice-Hall, Inc. $192 \mathrm{p}$.
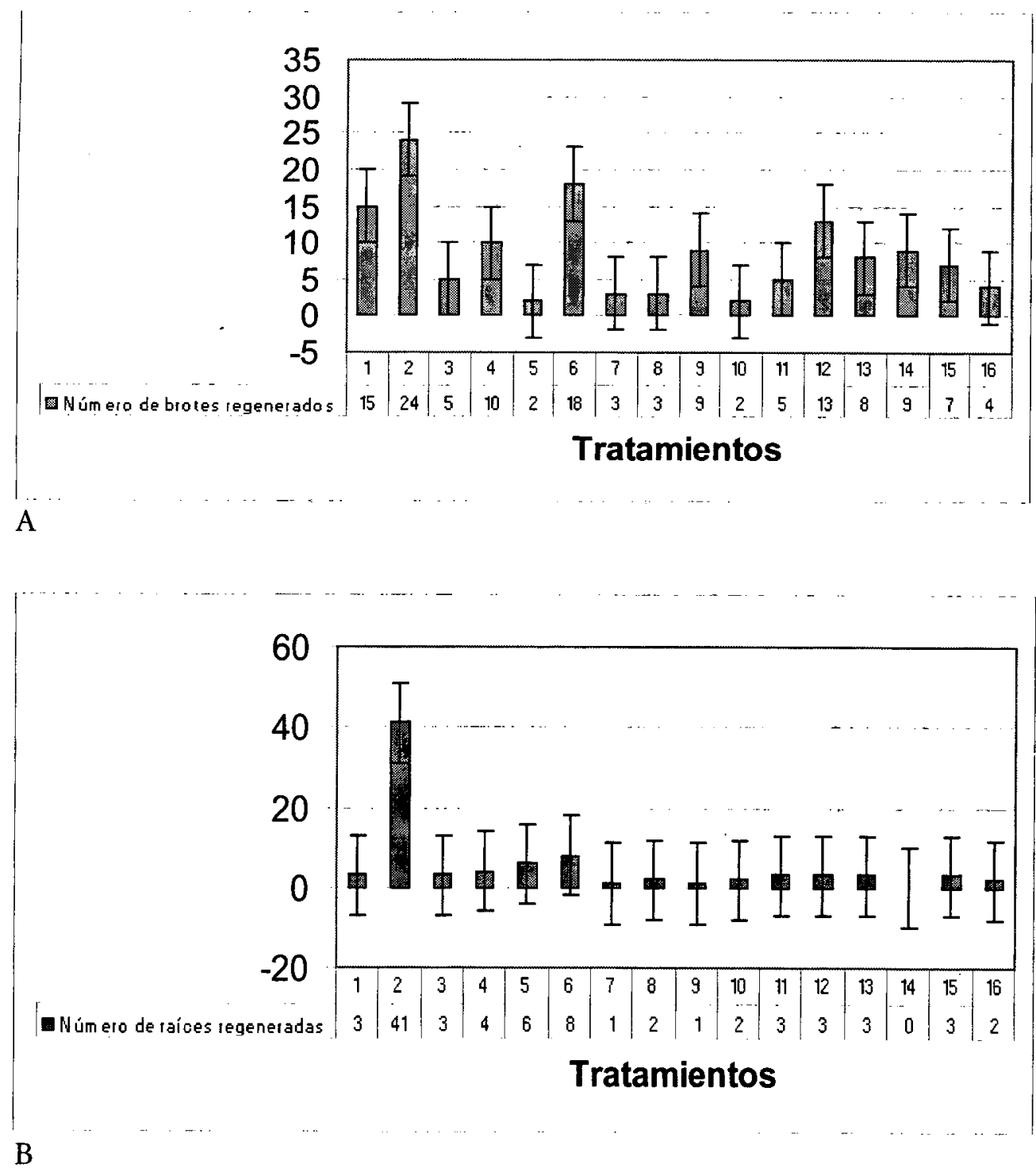

Figura 1. Efecto del Acido Indol Butirico (AIB) y la Bencil Amino Purina (BAP) en A. Proliferación de brotes (D. $S=5)$ y B. Inducción de raices regeneradas $(D . S=10)$. 


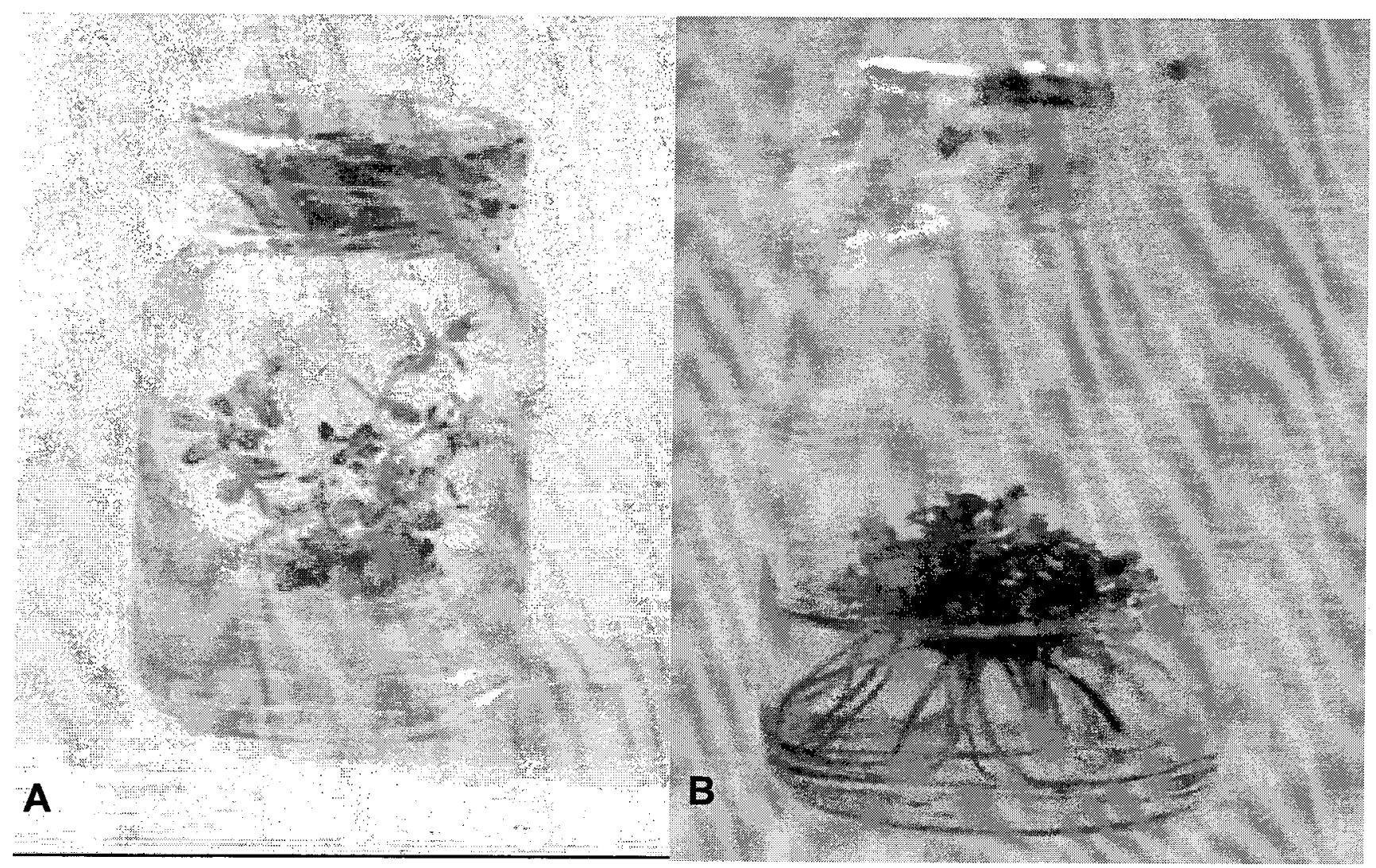

Figura 2. Efecto de $0.0 \mathrm{mg} \cdot \mathrm{L}^{-1}$ de Acido Indol Butírico $(A / B)$ y $0.5 \mathrm{mg} . \mathrm{L}^{-1}$ de la Bencil Amino Purina $(B A P)$ en $\mathbf{A}$. Caulogénesis (barra = $0.5 \mathrm{~cm}$.) y B. Rizogénesis (barra $=0.5 \mathrm{~cm}$.).

Herman, E. (2005). Recent Advances in Plant Tissue Culture IX: Media and Techniques for Growth, Regeneration and Storage 2002-2005. Estados Unidos : Agritech Consultants, INC. 129 p.

Instituto Alexander von Humbolt. (1997). Informe nacional sobre el estado de biodiversidad: Especies de plantas superiores amenazadas. Colombia. $391 \mathrm{p}$.

Jiménez, E. A. (1998). Cultivo de ápices y meristemos. En: Pérez Ponce, J. N (ed). Propagación y mejora genética de plantas por biotecnología. Cuba: Instituto de biotecnología de las plantas, pp. 45-56.

Jiménez, V. M; Castillo, J; Tavares, E; Guevara, E; Montiel, M. (2004). Micropropagación de Guadua angustifolia Kunth a partir de explantes nodales. Memorias del Simposio Internacional de Guadua 2004. Universidad Tecnológica de
Pereira, Colombia; septiembre 27 a octubre 2 de 2004.

Marulanda, M. L. (2004). Establecimiento in vitro de Heliconias con fines de producción masiva UTP. Scientia-et Technica año X, núm. 26.

Murashige, T.; Skoog, F. (1962). A revised medium for rapid growth and bioassays with tobacco tissues cultures. Physiol. Plant. 15, pp. 473-479.

Okada-Katsuo, A. (2001). La biodiversidad y los peligros que la amenazan. En: Perea Dallos Margarita (ed). Biotecnología agrícola: Un enfoque hacia el mejoramiento de plantas. Bogotá: Editora Guadalupe, pp. $29-41$.

Olivera, Z.V. (2000). Cultivo in vitro de Gerbera (Gerbera Jamesonii H Bolus) y su aclimatación en invernadero. Bioagro: México. 12, 75 p. 
Orellana, P. (1998). Propagación vía organogénesis. En: Pérez Ponce, J. N. (ed). Propagación y mejora genética de plantas por biotecnología. Santa Clara, Cuba: Instituto de Biotecnología de las Plantas; pp. 151-178.

Pedersen, C.; Brandt, K.; Saniewski, M. (1992). A method for disinfection of underground rhizome tips of Alstromelia and Heliconia. Acta horticulture. 325, pp.: $499-504$.

Pedroza, J.; Fernández, C.; Suárez, A. (2005). Evaluation of the effect of three growth regulators in the germination of Comparettia falcata seeds under in vitro conditions. In Vitro Cell. Dev. Biol. Plant. 41, pp. 838-843.

Pérez P.; Jiménez, G. E. (1995). Micropropagación y Fundamentos teóricos prácticos del cultivo in vitro. En: Conferencias en biotecnología agrícola; pp. 1-10 y 1-6.

Rodríguez, E. I.; Rodríguez, F. (2003). Propagación in vitro de Artemisa absinthium L. en Cuba. Centro de Investigación y desarrollo de medicamentos Rev. Cubana. Med. 6, pp. 6-13.

Salisbury, F.; Ross, C. (2000). Fisiologia Vegetal: Desarrollo de las plantas y fisiología ambiental. España: Thomson editores Paraninfo, S. A., pp. 573-574.
Segura, J. (2000). Morfogénesis in vitro. En: Azcon, J. y Talon, M. (eds.). Fisiología y bioquímica vegetal. España: Mac Graw Hill, pp. 381-392.

Steel, R.; Torrie, J. (1985). Bioestadística: Principios y procedimientos. 2 ed. Bogotá: McGraw Hill, pp. 328-367.

Taiz, L.; Zeiger, E. (1998). Plant physiology. 2 ed. Sunderland: Sinanuer Associates, Inc. 560 p.

Tapia, C. (2004). Iniciación de algunas especies de interés comercial en Chile e iniciación in vitro de Herbetia lahue una iridacea chilena de interés ornamental, Revista Chilena de Biología, núm. 5.

Uribe, M.; Cifuentes, L. (2004). Aplicación de técnicas de cultivo in vitro en la propagación de Legrandia concinna. Bosque (Valdivia). 25(1), pp. 129-135.

Vadillo G. (2004). Viabilidad y germinación de semillas de Puya raimondii Harms (Bromeliaceae). Facultad de Ciencias Biológicas UNMSM. Revista Peruana de Biología. 11(1), pp. 71- 78.

Yépez, E.; Vargas, E. (2003). Notas preliminares sobre la propagación clonal in Vitro de Agave Arizónica. Universidad central de Venezuela. Facultad de ciencias. Instituto de Biología Experimental. Revista Venezolana de Biología, núm. 3. 